\title{
EVALUATION OF URBANIZATION INFLUENCES ON URBAN WINDS OF KENYAN CITIES *ONGOMA, V., ${ }^{1}$ MUTHAMA, N. J., ${ }^{2}$ and GITAU, W. ${ }^{2}$ \\ http://dx.doi.org/10.4314/ejesm.v6i3.1
}

Received 27th July 2012; accepted 12th March 2013

\begin{abstract}
Most cities in Africa's developing countries are evidently growing leading to significant modification on climate over the cities that affect human comfort and his environment. Proper urban atmospheric planning and management are thus key to making cities environmentally sustainable. To achieve all these, urban weather and climate needs continuous monitoring to offer accurate, reliable and timely update of any significant changes. This study examined the modification of wind speed and direction by urbanization process. There is need to understand the modification of wind since the wind spped and direction greatly affects dispersion of pollutants in the city and distribution of heat which affect human comfort. The study utilized land surface albedo, decadal population data and daily wind speeds and direction. The wind was analyzed using wind rose plot and the population and albedo analyzed by carrying out trend analysis. The urbanization is evidenced by the reducing urban land surface reflectivity and the increasing population. Wind direction does not show modification by urbanization, however, its magnitude has exhibited a reduction with time. The reduction in wind speed is harmful to human and animal comfort and the environment at large. Practical approaches such as proper planning of the cities to minimize further modification by urbanization have been made. The choice of residential and industrial places is also emphasized with regard to these findings. The findings of this work are thus important for multi-sectoral use in the urban centres in Kenya.
\end{abstract}

Key Words: Urbanization, Comfort, Pollution, Modification, Albedo, Urban Heat Island

\section{Introduction}

Urban and suburban centers are observed to grow as a result of population growth; it involves land-use changes as a result of human activities. According to García et al., (2009), urbanization in many parts of the world is evident due to the increase in population in cities. This process creates climate of its own by producing a change in the nature of the surface and atmospheric properties of a region.

Kenya is experiencing rapid urbanization growth just like many other developing countries in Africa (UN Habitat, 2008). The effect of urbanization on the microclimate of cities are mostly due to the changes in the various land uses to which urban areas are put to, especially when these cities are compared to their surrounding countryside (Nduka and Abdulhamed, 2011).

Africa has a larger urban population than Northern America and close to two-fifths of its population in urban areas (UN, 2006). According to Oke (1973), urbanization effects on weather and climate are noticeable even in population settings of as small as 1000 people and the intensity of urban heat island (UHI) is linearly correlated with the logarithms of the population.

The potential for steadily increasing temperatures and air pollution coupled with a projected doubling of the global urban population by 2030 (UN, 2001), greatly elevates the need for inhabitants, public health officials, planners and decision makers to devise effective strategies of managing climate in large cities. The study of the effects of land surface change on the climate of a given area is thus very important.

The aim of the study was to evaluate the influence of urbanization on urban climate wind over Kenyan cities: Nairobi, Kisumu and Mombasa. This study is vital in enhancement of human comfort as well as ensuring environmental sustainability. Proper urban planning is the key to making cities environmentally sustainable, economically vibrant, and habitable.

\section{Study Area}

Kenya is located in Eastern part of Africa $\left(5^{\circ} \mathrm{N}, 4^{\circ} 40^{\prime} \mathrm{S}\right.$ and $\left.33^{\circ} 53^{\prime} \mathrm{E}, 41^{\circ} 55.5^{\prime} \mathrm{E}\right)$ and has a

${ }^{1}$ Kenya Meteorological Department 
total area of $582,646 \mathrm{~km}^{2}$. The study focused on the three Kenyan cities: Nairobi, Mombasa and Kisumu. Nairobi is centrally located in the country $\left(1^{\circ} 9^{\prime} \mathrm{S}, 1^{\circ} 28^{\prime} \mathrm{S}\right.$ and $\left.36^{\circ} 4^{\prime} \mathrm{E}, 37^{\circ} 10^{\prime} \mathrm{E}\right)$ and covers an area of 684 square kilometres; it holds a population of 3.1 million people (KNBS, 2010). It is the country's capital and largest city. According to Opijah et al., (2007), the predominant easterlies over Nairobi are associated with precipitation occasioned by moisture inflow into the country from the Indian Ocean. During December to February, the Northeast monsoons are common, and to an extent, the Southeast monsoons in June to August, are generally associated with depressed rainfall conditions.
Mombasa is Kenya's second largest city, located on the South Eastern coast of the country, along the Indian Ocean $\left(3^{\circ} 80^{\prime}, 4^{\circ} 10^{\prime} \mathrm{S}\right.$ and $39^{\circ} 60^{\prime}$ and $\left.39^{\circ} 80^{\prime} \mathrm{E}\right)$. The city has an area of $295 \mathrm{~km}^{2}$ and a population 939370 people (KNBS, 2010).

Kisumu is a port city $\left(0^{\circ} 6 \mathrm{~S}, 0.1^{\circ} \mathrm{S}\right.$ and $\left.34^{\circ} 45^{\prime}, 34.75^{\circ} \mathrm{E}\right)$ in western Kenya at an altitude of $1,131 \mathrm{~m}$, with a population of 968,909 people (KNBS, 2010). It is the third largest city in Kenya and the principal city of western Kenya. The city covers an area of approximately $417 \mathrm{Km}^{2}$, of which $297 \mathrm{Km}^{2}$ is dry land and approximately 120 $\mathrm{Km}^{2}$ under water.

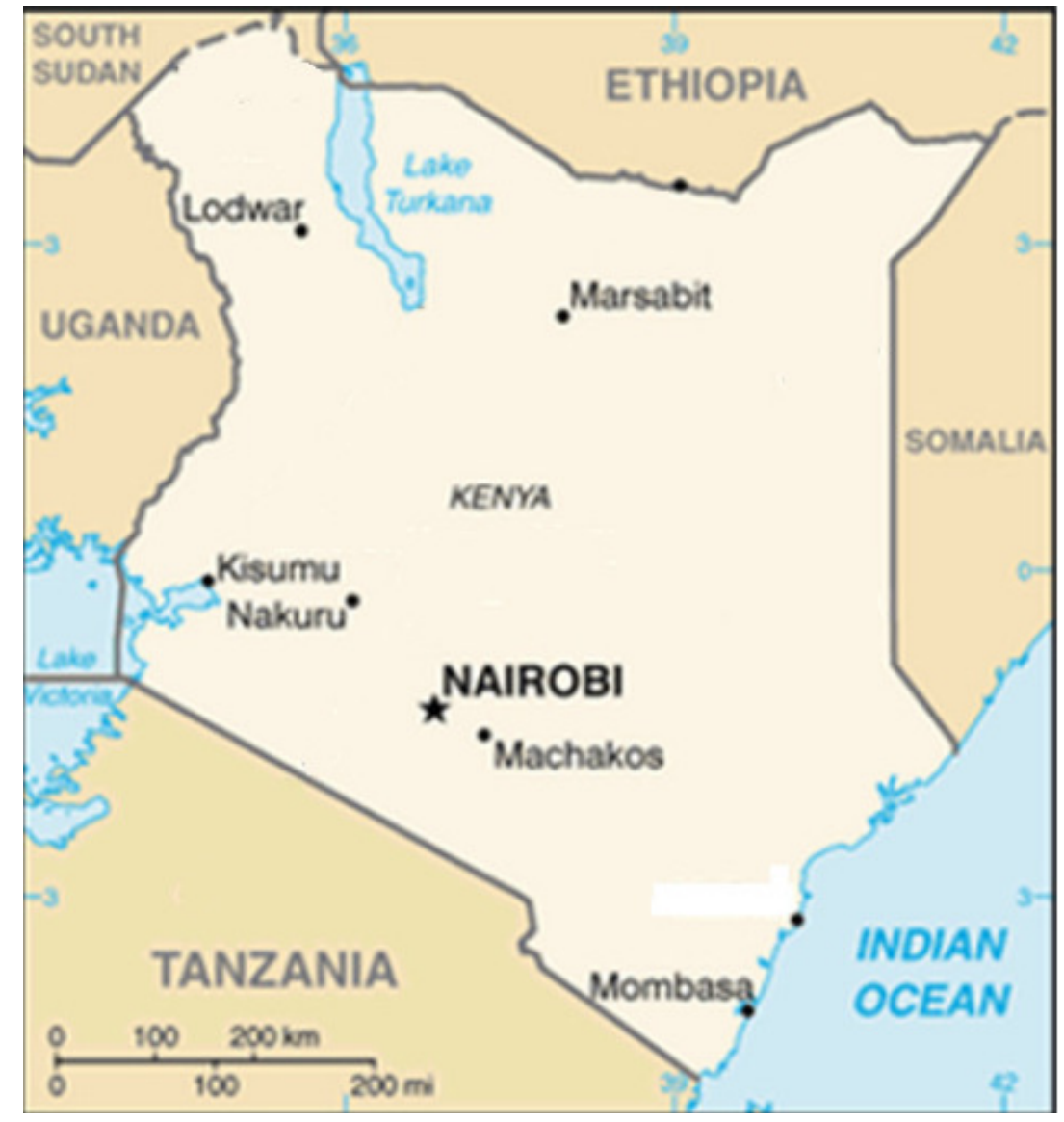

Figure 1 Map of Kenya showing the positions of Nairobi, Kisumu and Mombasa

\section{Methodology}

The data used in the study can be grouped into three classes namely directly observed weather data, satellite observed data and demographic data. The main limitation in the available demographic and satellite data sets is that the data is too short to conclusively correlate to the change in the climate parameters.

Hourly wind data sourced from Kenya Meteorological Department (KMD) for a number of representative stations (Table 1) was utilized dating from 1980s to 2010s. 
Table 1 Meteorological Stations used in the Study

\begin{tabular}{llllll}
\hline Station & Altitude & Longitude & Latitude & \multicolumn{2}{c}{ Data length } \\
& & & & From & To \\
\hline Moi Air Base & 1637 & 36.867 & -1.267 & 1975 & 2008 \\
Dagoretti Corner & 1798 & 36.750 & -1.300 & 1975 & 2010 \\
Wilson & 1676 & 36.820 & -1.320 & 1975 & 2010 \\
Jomo Kenyatta International Airport & 1615 & 36.920 & -1.320 & 1975 & 2010 \\
Kabete Agromet & 1941 & 36.750 & -1.270 & 1975 & 2008 \\
Muguga KARI & 2096 & 36.630 & -1.220 & 1975 & 2010 \\
Kisumu Airport & 1149 & 34.580 & -0.100 & 1975 & 2010 \\
Suba Meteorological Station & 1143 & 34.130 & -0.420 & 1980 & 2010 \\
Mtwapa & 21 & 39.733 & -3.930 & 1975 & 2008 \\
Mombasa International Airport & 5 & 39.620 & -4.030 & 1975 & 2010 \\
Malindi & 20 & 40.00 & -3.230 & 1975 & 2010 \\
Lamu & 6 & 40.900 & -2.270 & 1975 & 2010 \\
\hline
\end{tabular}

Land surface reflectivity was obtained from Moderate-resolution Imaging Spectrometer (MODIS). The monthly data spanning from August 2002 to December 2005 was acquired at a resolution of $500 \mathrm{~m}$. The actual reflectivity was obtained getting the difference between the reflectivity recorded under total sky and under clear sky.

Population data was obtained from the Kenya National Bureau of Statistics dating from 1969 to 2009 for the population census results of 1969 , 1979, 1989, 1999 and 2009 and population projections for years between the census years.

Wind Rose Plot (WRPLOT) View used in the study is a windows program that generates wind rose statistics and plots for selected meteorological stations for user-specified date and time ranges (Lakes Environmental, 2000). The software has a frequency count that displays in tabular form the number of occurrences of winds in each of 16 direction sectors and 6 wind speed classes for a given location and time period. It also has a frequency distribution tab which gives a table displaying the normalized frequency of occurrences of winds in each of 16 directions and 6 wind speed classes.

\section{Results and Discussions}

The change in surface albedo is an indicator of the land surfaces activities; the different types of land cover have different extents of reflectivity to incoming solar radiation. The land use changes in urban centers have a lower albedo than rural areas with trees and vegetation.

Kenyan cities have experienced different rates of urbanization with time from August 2002 to March 2005 (Figure 2).

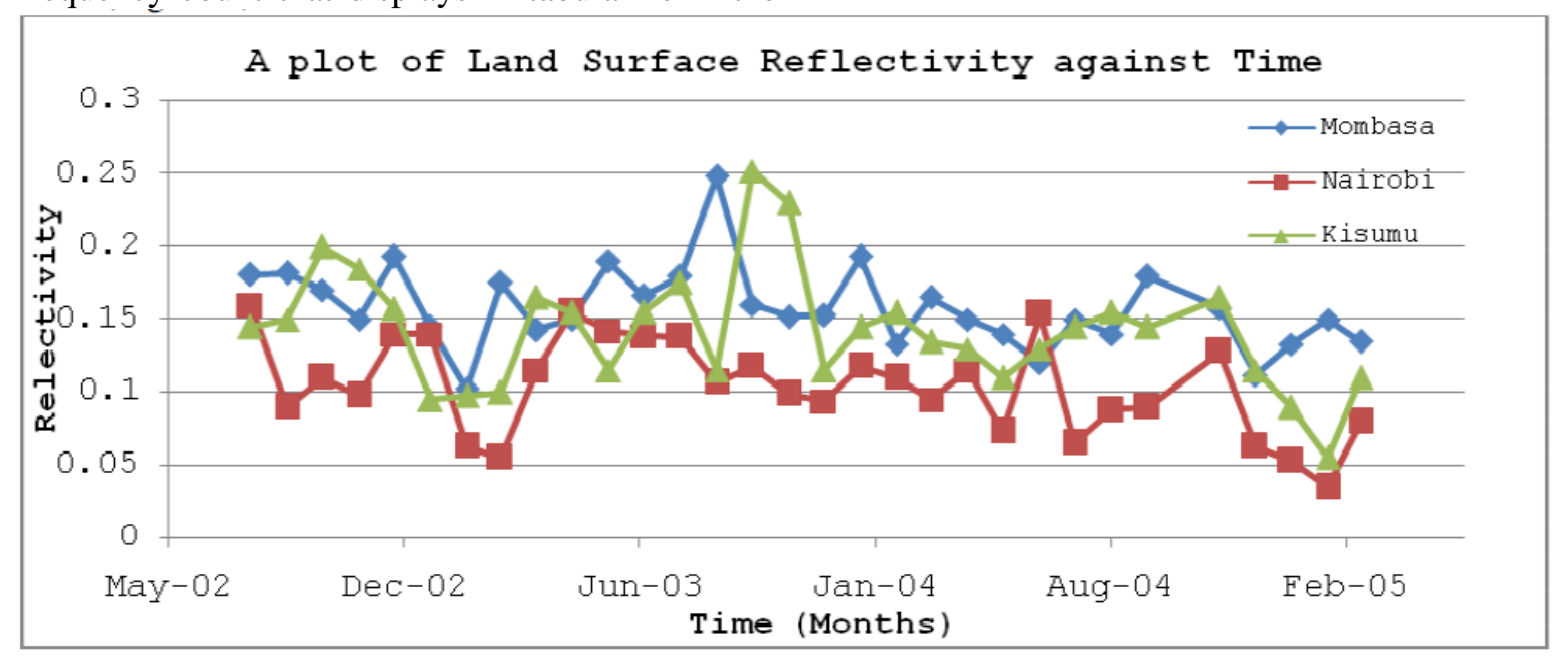

Figure 2 Land Surface Reflectivity over Kenyan Cities 
The reflectivity is generally lowest over the city of Nairobi and highest over Mombasa city. The complicated urban surface geometries decrease the rate of reflectivity in comparison to the former or the neighboring horizontal surface. Albedo changes with land use and is expected to decrease with the growth in the city. This is due to the dense building regions that have canyon effect, which not only affects wind speed but also causes multiple reflections for solar photons, limiting the number of solar photons reflected back to atmosphere. This observation is in conformity with a study carried out by Arnfield (1982).
The albedo values over the three cities were mainly confined between 0.04 and 0.25 with the means of $0.156,0.142$ and 0.104 for Mombasa, Kisumu and Nairobi cities respectively. The result closely agrees with the findings by Oke (1987), in his study, he measured values of albedo in urban areas and found out that they range from 0.10 to 0.27 , with a mean near 0.15 .

Population trend over the three cities depict an increase with the city of Nairobi experiencing the highest growth (Figure 3). The population increase indicates urban growth which induces changes in land use.

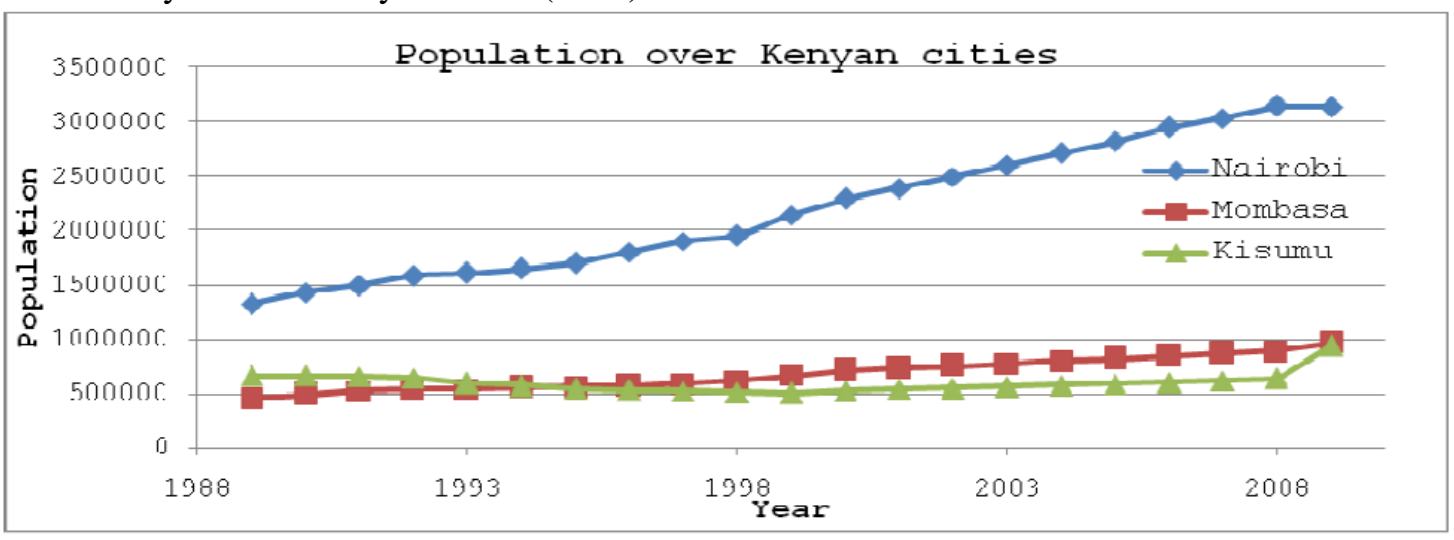

Figure 3 Population trends over Kenyan Cities

The city with highest population; Nairobi is thus regarded to be the highly urbanized in comparison with the rest. It is thus expected that the impacts of urbanization on urban climate will be most pronounced over Nairobi city. According to CBS (2001), Nairobi's population is projected to hit 3.8 million by 2015 . This will increase pressure on the available resources.

\section{Effects of Urbanization Wind}

Wind roses were used to identify and study changes in wind speed and direction. This was done by comparing the wind speeds of the past years with an equal number of current years. Wind class frequency distributions were similarly produced for the past and an equal number of recent years to study change in wind speeds.

The predominant winds over Nairobi are Easterlies; it thus implies that pollutants dispersed from the city are mainly transported to the western parts of the city (Figure 4). It is therefore advisable that industries and factories should be located to the western parts of the city of Nairobi to minimize the exposure of city residents to the pollutants.
The wind direction is noted to have remained constant throughout the study period indicating that urbanization has no significant influence on wind direction.

Over the city of Nairobi, the wind speed class of highest frequency in the earlier years; 1995 to 1997 is $5.7-8.8 \mathrm{~m} / \mathrm{s}$ at 44.0 per cent followed by $3.6-5.7 \mathrm{~m} / \mathrm{s}$ percent at 36.6 per cent and then 8.8 $-11.1 \mathrm{~m} / \mathrm{s}$ at 10.4 per cent (Figure 5).

In the recent years; 1998 to 2000, the predominant wind speed class is $2.1-3.6 \mathrm{~m} / \mathrm{s}$ at $50.2 \%$ followed by $3.6-5.7 \mathrm{~m} / \mathrm{s}$ at 41.0 per cent and then $0.5-2.1 \mathrm{~m} / \mathrm{s}$ at 7.8 per cent (Figure 5). There is a notable decrease in wind speeds when comparing the wind speeds of the past years and wind speeds of the recent years. The highest frequency of wind speeds changed from wind class of $5.7-8.8 \mathrm{~m} / \mathrm{s}$ in the earlier years to 2.1 $3.6 \mathrm{~m} / \mathrm{s}$ in the recent years. The reduction of wind speeds in attributable to urbanization; increase in surface roughness owing to increase in the density of structures in the urban centre and other forms of land use. 


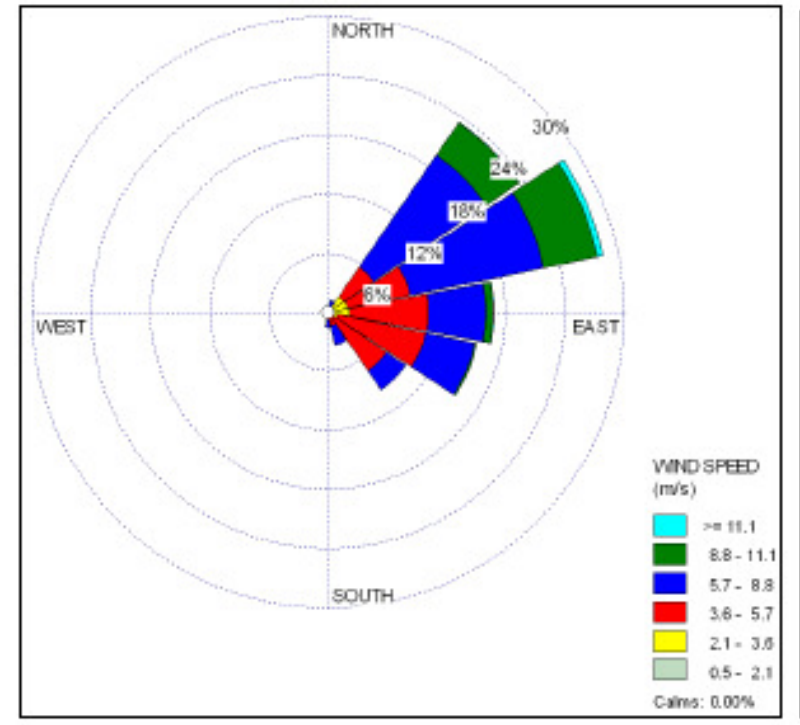

(a)

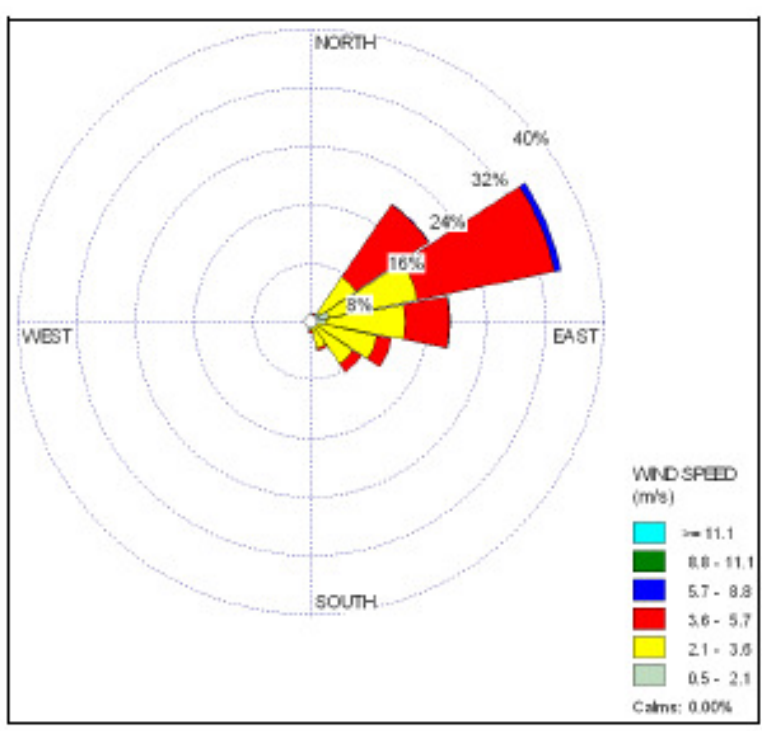

(b)

Figure 4 Nairobi City wind roses for (a) 1991 - 2000 (b) 2001 -2010

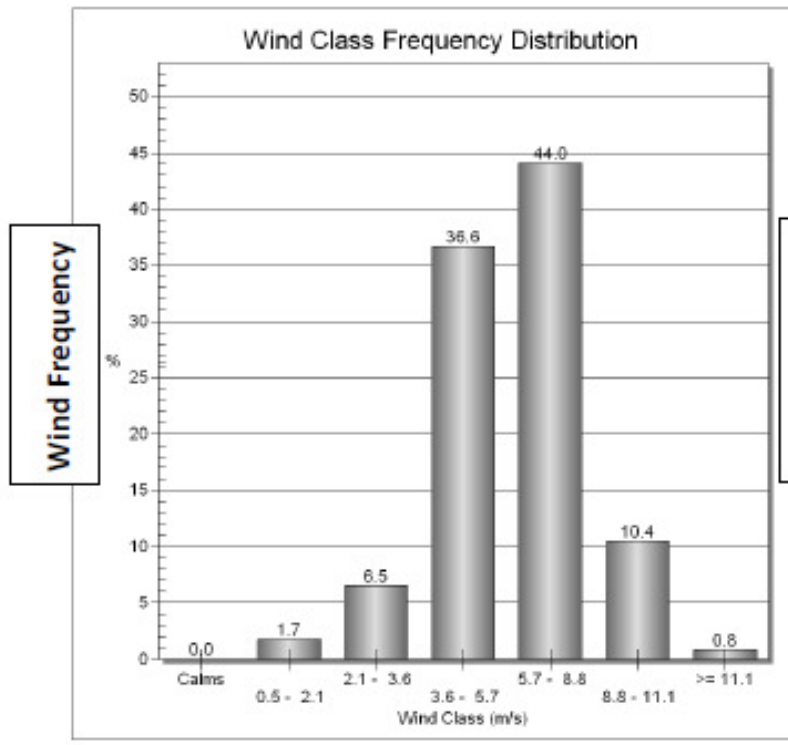

(a)

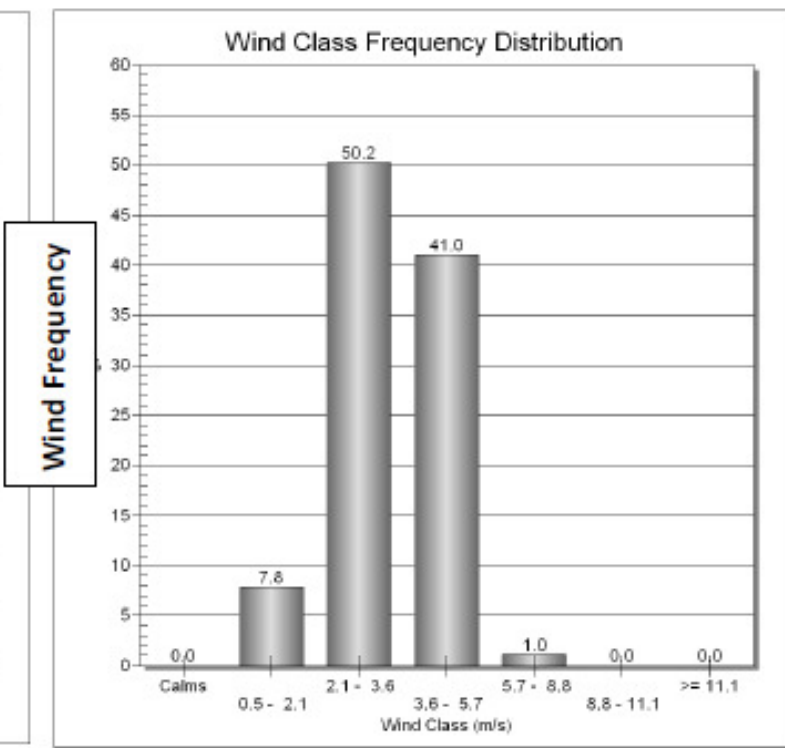

(b)

Figure 5 Nairobi City wind class frequency distribution for (a) 1995 - 1997 (b) $1998-2000$

South easterlies are the predominant winds over the city of Mombasa (Figure 6). The winds have not changed comparing the past years (1995 2002) and the current years (2003 - 2010). The dispersal of pollutants is mainly from the southeast to northwest. The highest concentration of pollutants is therefore expected to be in the northwestern environs of the city.

During the earlier years; 1995 to 2002, the wind class frequency of $5.7-8.8 \mathrm{~m} / \mathrm{s}$ is predominant wind speed at 53.7 per cent, followed by $3.7-5.7 \mathrm{~m} / \mathrm{s}$ at 32 per cent and $8.8-11.1 \mathrm{~m} / \mathrm{s}$ at 5.8 per cent (Figure 7).

The wind class frequency of $3.6-5.7 \mathrm{~m} / \mathrm{s}$ is predominant wind speed at 47 per cent, followed by $2.1-3.6 \mathrm{~m} / \mathrm{s}$ at 45.3 per cent and $0.5-2.1 \mathrm{~m} / \mathrm{s}$ at 4.3 per cent in the recent years; between the year 2003 and 2010 (Figure 7). There is a notable effect of urbanization on the wind observed over Mombasa city in the recent years. In the earlier 
years (1995-2002), the predominant wind class speed frequency is $5.7-8.8 \mathrm{~m} / \mathrm{s}$ at 53.7 per cent with 91.7 per cent of the wind speeds surpassing wind class frequency of $2.1-3.6 \mathrm{~m} / \mathrm{s}$ while in the recent years (2003 -2010), the predominant class $3.6-5.7 \mathrm{~m} / \mathrm{s}$ at 47 per cent with only 50.5 per cent of the winds exceeding wind class frequency of $1.2-3.6 \mathrm{~m} / \mathrm{s}$.

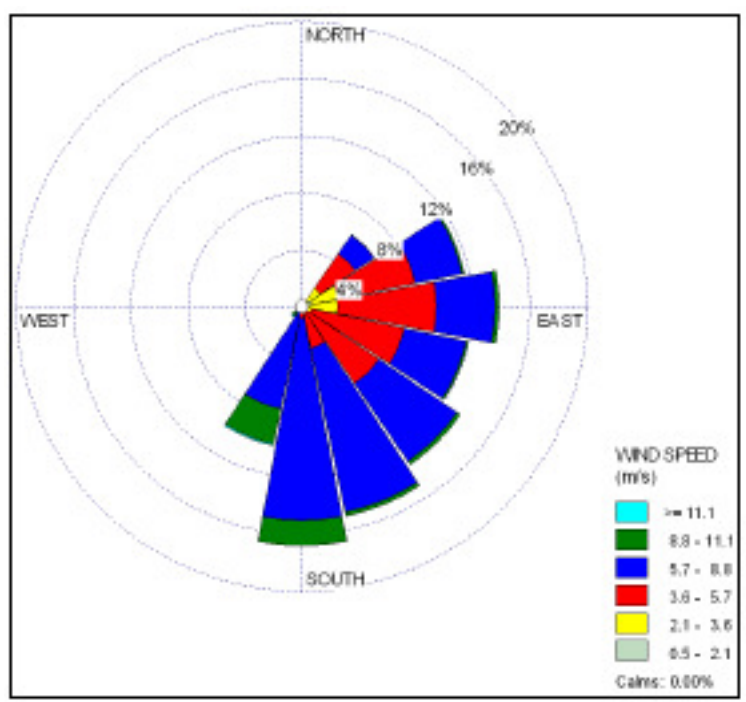

(a)

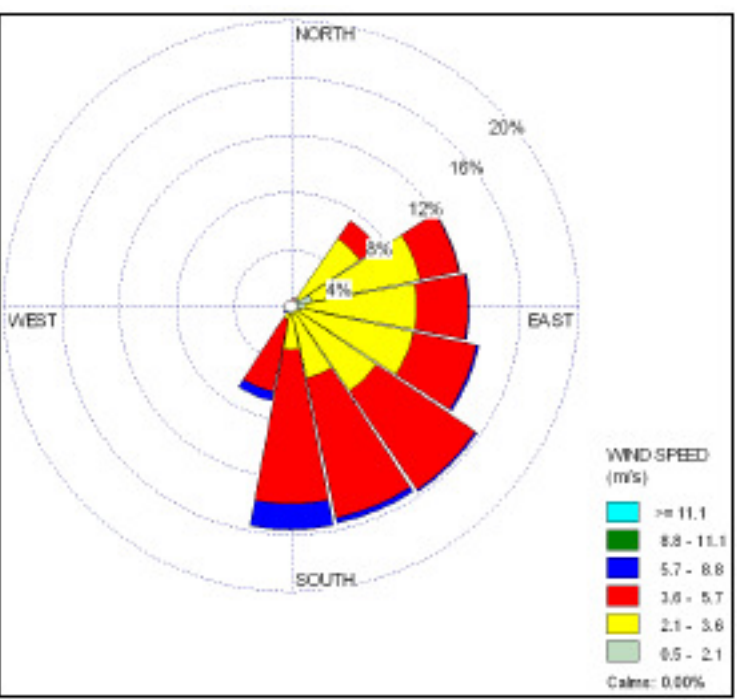

(b)

Figure 6 Mombasa City wind roses for (a) 1995-2002 and (b) 2003-2010

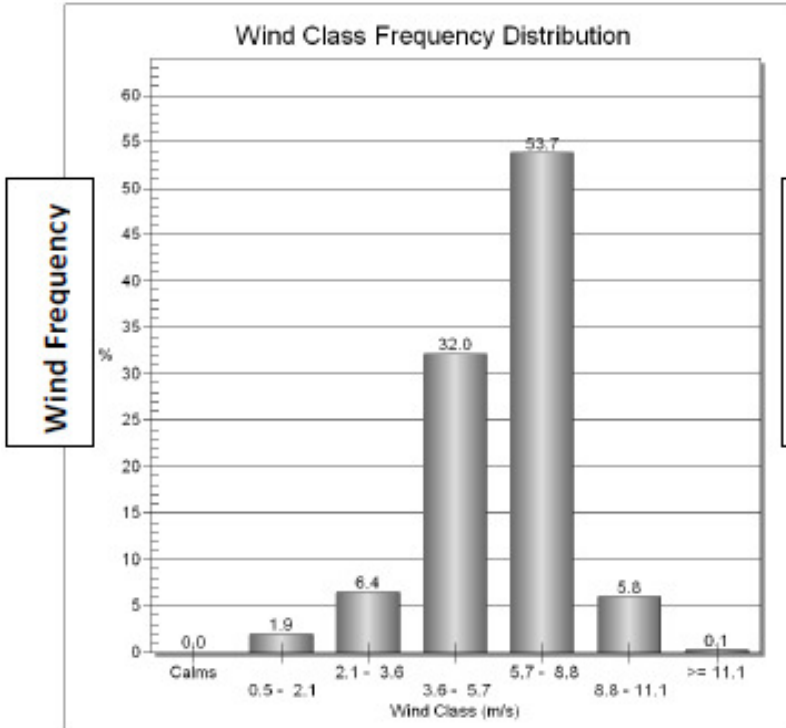

(a)

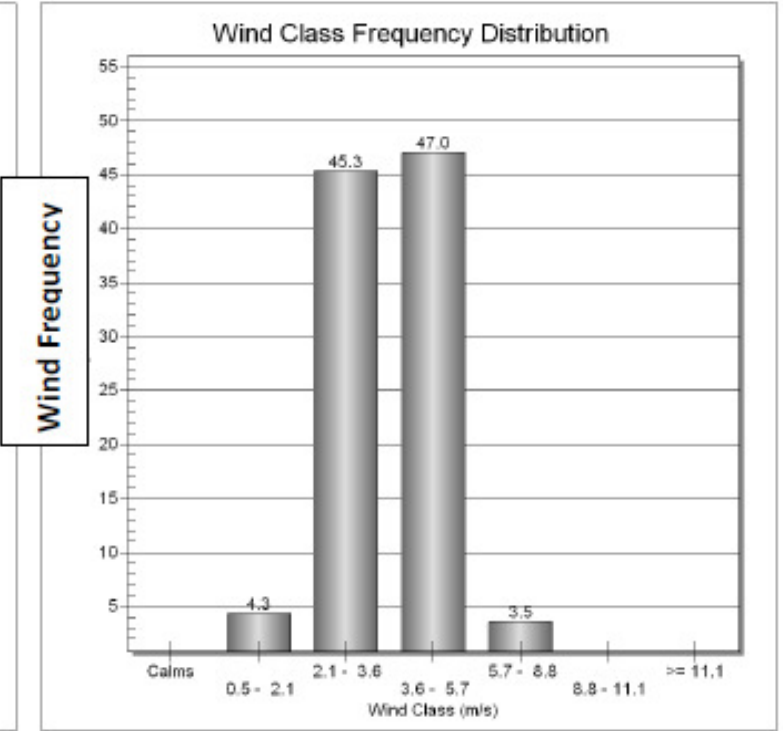

(b)

Figure 7 Mombasa City wind class frequency distribution for (a) 1995 - 2002 (b) $2003-2010$

The prevailing wind over the city of Kisumu is mainly easterly (Figure 8). The wind does not change in direction during the study period, a possible suggestion that urbanization has insignificant modification on the wind direction.
The wind speed over the city of Kisumu of highest frequency is between 2.1 and $3.6 \mathrm{~m} / \mathrm{s}$ throughout the study period. There is an observed changes in wind magnitude during the study with the recent years (2003-2010) experiencing a reduction in wind speed as compared to earlier 
years (1995-2002) (Figures 9). In the earlier years, 15 per cent of the winds recorded exceed the predominant wind class frequency while in the recent, 10 per cent does. The speed of winds below the predominant class has on the other hand increased by 6.1 per cent in the two categories with time.

The reduction in wind speeds over the urban centers in Kenya totally agrees with the observations made by Shepherd (2005) in United States. The winds get slower owing to the increased roughness of these areas; increased frictional drag on air flowing over built-up urban terrain, which is rougher than rural areas. Another difference between urban and rural wind flow is the convergence of low-level wind over a city, this is caused primarily by the horizontal thermal gradients of the urban heat island. Although wind directions could change as a result of the heat island circulations or the bending of the flow around and over the urban area, this has not been observed in Kenyan cities.

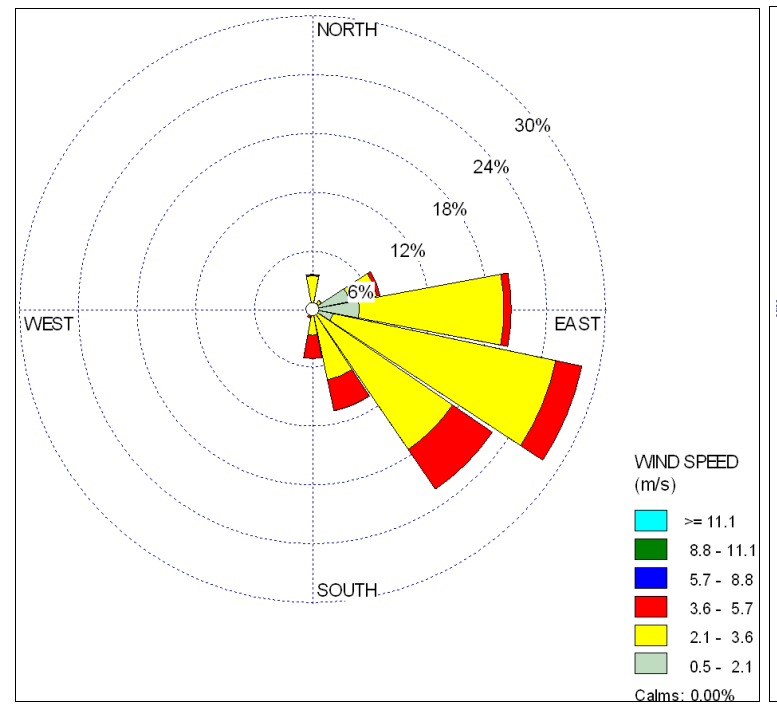

(a)

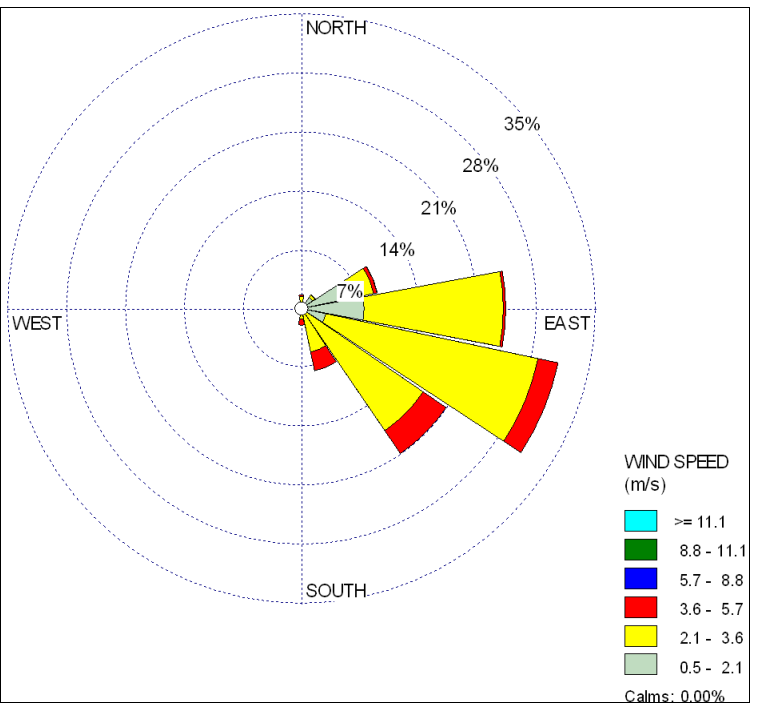

(b)

Figure 8 Kisumu City wind roses for (a) 1995-2002 and (b) 2003 - 2010

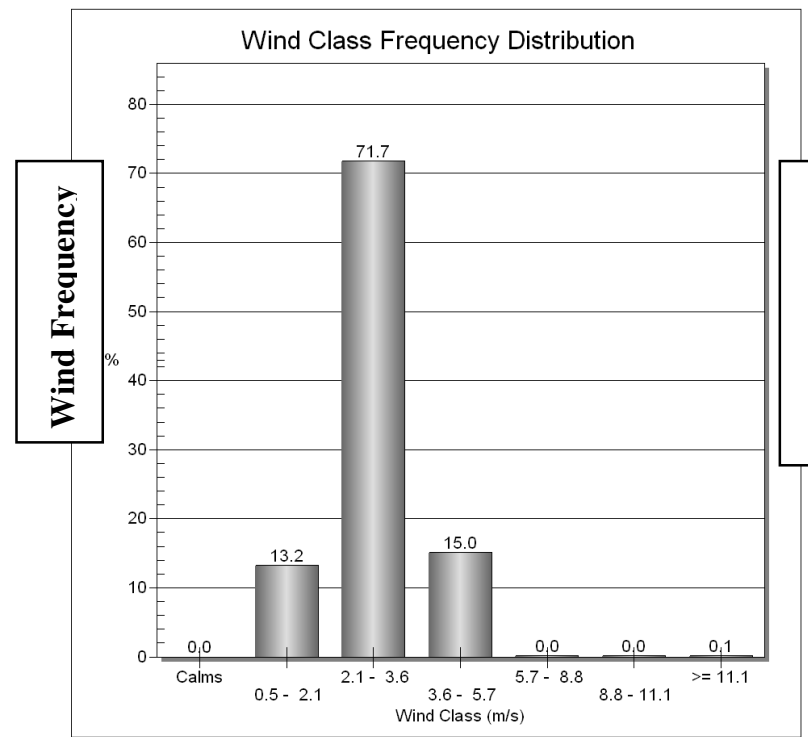

(a)

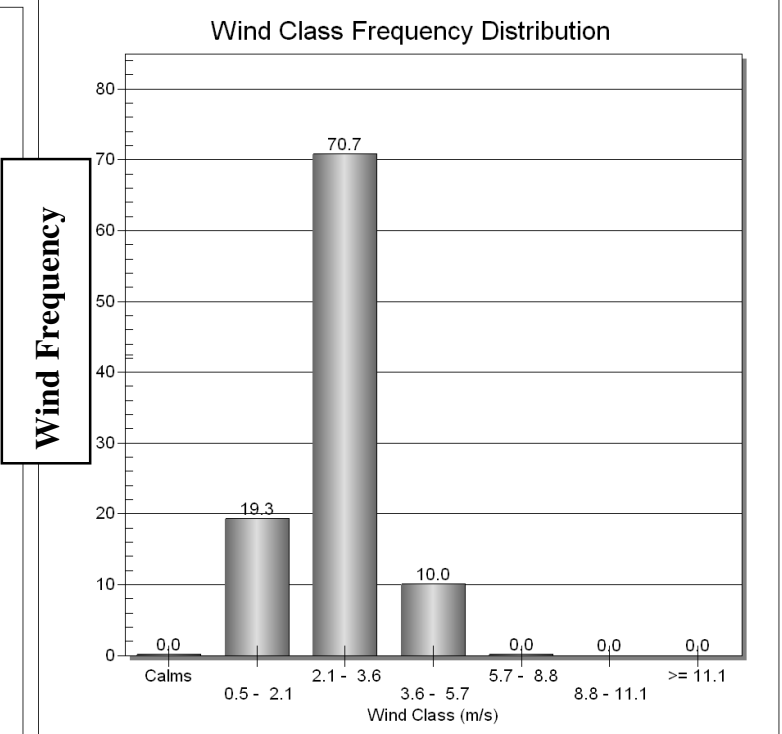

(b)

Figure 9 Kisumu City wind class frequency distribution for (a) 1995-2002 (b) 2003 - 2010 


\section{Discussion}

Urbanization is evident in Kenyan cities; it is evidenced by population and land surface reflectivity changes. Population growth in the Kenyan cities is partly explained by net migration into the city (CBS, 2003).

The land albedo is observed to decrease over the cities with time. This can be explained by the dense building regions that have canyon effect, which not only affects wind speed but also causes multiple reflections of solar photons limiting the number of solar energy reflected back to the atmosphere. This could also be due to the urban surfaces; concrete material has low albedo than the natural surface in broadband albedo.

The dominant winds over cities show a decrease speed with time although the directions remain constant. The reduction in wind speeds with the growth of the city is explained by change in surface roughness as well as enhanced temperatures that reduce pressures over the city forming a centre of low level convergence.

The observed decrease in wind speed due to land surface modification over the city reduces the transfer of heat and momentum. This has an effect of maintaining the levels of concentration of pollutants within a city as well as temperature levels. The increase in the rate of urbanization as a result of increased rural-urbanization is likely to further alter the micro-climates of the urban settings which will negatively affect human comfort.

\section{Conclusion and Recommendations}

The study of winds over these regions reveals that wind speed is modified by urbanization; wind speeds over the cities are observed to decrease with time. The wind direction over the cities showed no change over time indicating that urbanization has very little or no influence on wind direction.

The city of Nairobi has experienced the highest rate of reflectivity decrease indicating that the city is developing fastest as compared to the rest. The population over the three cites is as well observed to increase with time, with Nairobi having the highest increase and Kisumu having the least growth.

The dominant winds over the cities of Nairobi and Kisumu are easterlies while in the coastal city of Mombasa are mainly south easterlies. The western environs of the cities of Kisumu and Nairobi and the northwestern parts of the city of Mombasa experience high pollutions during the calms days and residents are thus advised to minimize outdoor exposure to the pollutants during the time.

Following the observed modification on urban climate by urbanization, the environmental effect of such urban weather modification on human comfort is thus inevitable. This information is therefore of value to building designers, city dwellers, event organizers, health practitioners, city planners among others to enhance safe stay and environmental sustainability. The awareness created by climate modification calls for environmentally conscious land use planning and risk reduction strategies. The planners and designers of structures in the cities should closely work with climatologists so as to incorporate wind speed and direction in their designs to enhance human comfort. Planners should also factor wind in the allocation of different economic activities to minimize pollution.

Acknowledgement

We thank the entire administration of the Department of Meteorology, University of Nairobi and Kenya Meteorological Department for the provision of data, encouragement and understanding at our respective places of work.

\section{References}

Arnfield, A. J. (1982), An approach to the estimation of the surface radiative properties and radiation budgets off cities. Phys. Geogr., 3, 97 122.

CBS (2001), Statistical Abstract. Central Bureau of Statistics. Ministry of Finance and Planning, Nairobi. Government Print Press CBS (2003), Statistical Abstract. Central Bureau of Statistics. Ministry of Finance and Planning, Nairobi. Government Print Press CBS (2009), Statistical Abstract. Central Bureau of Statistics Ministry of Finance and Planning, Nairobi. Government Print Press

García, O. R., Tejeda, A. M., and Bojórquez, G. M. (2009), Urbanization effects upon the air temperature in Mexicali, B. C., México. Atmósfera 22(4), 349-365

KNBS, (2010), Kenya Population Census, 2009. Ministry of State for Planning, National 
Development and Vision 2030, Nairobi. Government Print Press

Lakes Environmental, (2000), WRPLOT View Help Manual. [Available from http://www.lakesenvironmental.com (Accessed on $15 / 12 / 2011$ )

Nduka, I. C. and Abdulhamed, A. I., (2011), Classifying Urban Climate Field Sites by "Thermal Climate Zones", Research Journal of Environmental and Earth Sciences 3(2), 75 80.

Oke, T. R. (1973), City size and Urban Heat Island. Atmospheric Environment 7: 769 - 779

Oke, T. R. (1987), Boundary Layer Climates $2^{\text {nd }}$ edn., Methuen Co., London/New York, 435
Opijah, F. J., Mukabana, J. R.and Ng'ang'a, J. K. (2007), Rainfall Distribution Over Nairobi Area. JMRS, 1 (1), 3-13.

UN, (2001), World Urbanization Prospects: The 1999 Revision. United Nations, Washington, DC UN, (2006); World Urbanization Prospects: the 2005 Revision, United Nations Population Division, Department of Economic and Social Affairs, (POP/DB/WUP/Rev.2005), United Nations, New York

UN-Habitat, (2008), The State of African Cities; A Framework for Addressing Urban Challenges in Africa, UN Habitat, Nairobi University press, Cambridge, UK and New York, NY, USA. 